\title{
Transição agroalimentar em comunidades tradicionais rurais: o caso dos remanescentes de quilombo Kalunga - GO
}

\author{
Rodrigo de Jesus Silva ${ }^{1}$, Maria Elisa de Paula E. Garavello ${ }^{2}$, Rafael Navas ${ }^{2}$, Gabriela B. \\ Nardoto $^{3}$, Edmar A. Mazzi ${ }^{4}$ e Luiz A. Martinelli ${ }^{4}$
}

O maior acesso ao meio urbano e ao mundo globalizado pode estar colocando em risco o modo de vida das comunidades tradicionais rurais, gerando impactos consideráveis em seus sistemas agroalimentares. Assim, o objetivo deste trabalho foi avaliar as consequências do desenvolvimento nos sistemas agroalimentares de comunidades tradicionais devido ao aumento da urbanização, do maior acesso à economia de mercado e políticas públicas, por meio da caracterização dos hábitos alimentares e formas de produção de autoconsumo. O estudo foi conduzido nos remanescentes de quilombo Kalunga - GO, por intermédio da adaptação do método "recordatório alimentar 24 horas" e observação participante, onde foram caracterizadas as condições socioeconômicas e os sistemas agroalimentares locais. A partir disso, foi possível identificar elementos de transição agroalimentar nas comunidades mais acessíveis ao meio urbano, ou seja, mudanças na produção de autoconsumo e hábitos alimentares locais. Em contraposição, em algumas comunidades foi identificado um panorama de resistência do modo de vida tradicional e reorganização por meio de estímulos à produção agroextrativista.

Palavras-chave: sistema agroalimentar, uso dos recursos naturais, agroecossistemas tradicionais.

\section{Agro-food transition in the traditional rural communities: the case of slaves remnants Kalunga - GO}

The greater access to urban and globalized world may be endangering the livelihood of traditional people, generating impacts on food and agro-food system. The objective was to evaluate the consequences on agro-food system of traditional communities due to increased urbanization, income, greater access to the market economy and public policy, through the characterization of food habits and production of auto-consumption. The study was conducted in the remaining slaves Kalunga - GO. Using one adapted "food 24h recall" method andfield participative observations were characterized the local socioeconomic conditions and local agro-food system. From this, was possible to identify elements of agro-food transition on accessible communities, in other words, changes in the wholly system of natural resource use, self-consume production and food habits. In contrast, in

\footnotetext{
${ }^{1}$ Universidade Federal do Acre. Correspondência: Distrito Industrial, CEP: 69920-900, Rio Branco, AC, Brasil. Tel. (68) 3228-1234/9904-9545. E-mail: rodrigojsilva7@gmail.com.

2 Departamento de Economia, Administração e Sociologia, ESALQ, USP.

${ }^{3}$ Universidade de Brasilia. Correspondência: Faculdade UnB Planaltina, Área Universitária 1, Vila Nossa Senhora de Fátima Planaltina, CEP: 73340-710, Brasília, DF, Brasil. 
some communities the resistance of traditional way of life and reorganization was identified through incentives for agro-extractive production and other economic activities related to local culture.

Key-words: food habits, traditional culture, local people.

\section{INTRODUÇÃO}

Os alimentos carregam consigo significados culturais que dentre todos os aspectos da cultura material talvez seja um dos que mais se encontra subjacente a todo o campo de ação humana [1,2]. Estudos referentes ao tema avaliam a alimentação de comunidades tradicionais a partir de uma série de variáveis de influência nos hábitos alimentares, como a diversidade de itens alimentares disponíveis, a habilidade no manejo e uso dos recursos naturais como segurança alimentar e a interferência de fatores socioculturais $[3,4,5]$.

Contudo, por meio do sistema de produção e transformação agroalimentar moderno a industrialização pode estar desvinculando o alimento da natureza e o comedor do seu universo biocultural [6. Para alguns autores, uma consequência de tal fenômeno é uma possível homogeneização dos hábitos alimentares e da cultura, o que pode acarretar em um macro padrão de transformação dos hábitos alimentares e produção de subsistência de comunidades tradicionais rurais $[7,8,9,10]$.

Segundo alguns autores, os agroecossistemas manejados pelas comunidades tradicionais se desenvolveram ao longo de séculos de evolução biológica e cultural por meio de experiências acumuladas durante a interação direta com o meio ambiente, sem o auxílio de insumos externos, como: capital e conhecimento científico [11, 12]. Nestes agroecossitemas tradicionais, onde as culturas agrícolas sofrem pressão de ordem natural somente, o sistema não se encontra artificializado, pois mantém muito das características de um ecossistema natural [13].

Apesar da variação histórica e geográfica peculiar a cada cultura, os agroecosssistemas tradicionais conjugam inúmeras características semelhantes, como: produção de autoconsumo, baixos insumos agrícolas e tecnológicos, grande diversidade de cultivares, uso de recursos naturais locais, dentre outros ${ }^{[14]}$. A variedade de espécies cultivadas nos agroecossistemas tradicionais é um elemento chave para sustentabilidade agrícola e diminuição da demanda por insumos externos [13], pois reúne todo um complexo biocultural de uso dos recursos naturais de subsistência que pode auxiliar na conservação da biodiversidade [11, 14] e na reprodução sociocultural [15].

Para muitos pesquisadores, portanto, a alimentação é compreendida como o meio fundamental de automanutenção das condições socioeconômicas, culturais, e de adaptabilidade às condições sazonais e ambientais [3, 16, 17, 18]. Entretanto, com a modernidade, transformações significativas vêm ocorrendo na alimentação, sendo que em áreas rurais isoladas o processo tende a assumir peculiaridades relacionadas ao modo de vida tradicional de manejo dos recursos.

As comunidades tradicionais normalmente dependem do trabalho familiar para o próprio sustento e empregam tecnologias de pequeno impacto, como artesanato, lavoura, pesca e extrativismo, se pautam por outro modelo de visão de mundo, no qual natureza e sociedade são integradas, onde ambas emergem uma na outra de maneira simbiótica [19]. Por meio dessa relação de mundo tais comunidades adquirem um profundo conhecimento dos processos naturais, os quais lhes permitem estabelecer sistemas complexos de uso dos recursos naturais [20]. Há, portanto, na definição de populações tradicionais uma estreita relação com a questão ambiental de uso dos recursos naturais disponíveis para a subsistência.

Para Durham [21], a sociedade rural brasileira é caracterizada pela universalidade e presença de elementos tradicionais no modo de organização da unidade produtiva (família conjugal) em grupos de vizinhança e compadrio, nos padrões e técnicas simples de trabalho e na possibilidade de acesso ao meio de produção essencial que é a terra, voltada essencialmente à manutenção da vida em condições adversas de subsistência. No entanto, não há uma designação uniforme para as populações tradicionais, caracterizadas principalmente pela produção de subsistência, participação em uma ordem social tradicionalista e pela organização de grupos comunitários locais [21]. 
Diante das mudanças sociais globais em que o modo de vida das comunidades rurais tem se aproximado cada vez mais ao do meio urbano, os antropólogos questionam inclusive a validade do termo "tradicional". Numa perspectiva de preservação ambiental, discute-se que o conceito de culturas tradicionais ainda está em construção [22]. No Brasil, do ponto de vista legal, o termo aparece apenas recentemente, na Lei sobre a utilização e proteção da vegetação nativa do Bioma Mata Atlântica de 2006.

Neste cenário, a hipótese principal é que, devido ao maior acesso das comunidades à cidade, a transição alimentar, recorrente no meio urbano, seja acompanhada por mudanças na relação com a natureza, se reconfigurando numa forma mais complexa de transição. De tal forma, a suposição é que esse fenômeno pode estar alterando todo o sistema agroalimentar destas comunidades, as formas de produção de autoconsumo e uso dos recursos naturais de subsistência, tornando assim o manejo da terra, o extrativismo vegetal e animal cada vez mais reduzidos, colocando em risco a própria manutenção do modo de vida local.

Neste contexto de mudança, quais seriam os impactos da modernidade, do desenvolvimento econômico, da urbanização, das políticas públicas de transferência de renda, do maior acesso a itens industrializados de supermercado no modo de vida de comunidades tradicionais, em seus sistemas agroalimentares, hábitos alimentares e produção agrícola de autoconsumo? Assim, por meio de aplicação de questionários e observação participante em comunidades quilombolas o objetivo foi de caracterizar os hábitos alimentares locais e as formas de produção de autoconsumo, a fim de avaliar a influência do maior acesso ao meio urbano nos sistemas agroalimentares das comunidades. Diante disso, o intuito é reunir elementos de avaliação dos desafios impostos às comunidades tradicionais rurais ante ao amplo processo de modernização do campo e assim verificar as mudanças no modo de vida dessas comunidades tradicionais, especificamente nos remanescentes de quilombo do Sítio Histórico e Patrimônio Cultural Kalunga.

\section{MATERIAL E MÉTODOS}

\section{Áreas de Estudo e Amostragem}

O Sítio Histórico e Patrimônio Cultural Kalunga abrange uma área de 257.000 ha com cerca de
4.000 pessoas em seus limites [23]. Localizado no Bioma Cerrado, na Reserva da Biosfera do Cerrado no nordeste do estado de Goiás, Microrregião Homogênea da Chapada dos Veadeiros-005, na zona rural dos municípios de Teresina de Goiás, Cavalcante e Monte Alegre, região de fitofisionomia basicamente de Cerrado Rupestre com elevadas altitudes, solos rasos e ácidos, com grande número de afloramentos rochosos de arenito e quartzo que geram grandes empecilhos à expansão da agricultura, elevado grau de endemismo e espécies raras.

A formação do povo Kalunga remonta ao século XVIII, com a chegada dos bandeirantes Bartolomeu Bueno da Silva, o Anhanguera, e João Leite da Silva Ortiz, no estado de Goiás. Em busca do ouro, os bandeirantes instalaram os centros do garimpo, iniciando a mineração, que muito dependeu do trabalho escravo [24]. Segundo relatos dos próprios Kalunga, o quilombo surge a partir da fuga de escravos da mina Boa Vista, localizada no extremo norte do estado de Goiás, expandindo-se posteriormente com a migração, principalmente, de escravos alforriados [24]. Diante da conjuntura histórica do Brasil colônia, o isolamento geográfico dos Kalunga, além de possibilitar a sobrevivência, manteve tradições e costumes que nos remetem à África.

As unidades domésticas (UD) foram o foco de análise do presente trabalho, sendo amostradas de acordo com os moradores que concordaram com a participação. No total, 81 unidades domésticas (UD) foram avaliadas, representando em torno de 10\% dos domicílios existentes, de acordo com dados do Diagnóstico Situacional das Comunidades do Sítio Histórico e Patrimônio Cultural Kalunga [23].

Dos 48 agrupamentos quilombolas identificados [23] foram amostrados 11 para a pesquisa; perfazendo, aproximadamente, $1 / 4$ de toda a comunidade. A seleção dos 11 agrupamentos objetivou contemplar os 3 municípios pelo qual a comunidade se distribui - Monte Alegre, Teresina e Cavalcante - como forma de possibilitar assim uma amostragem representativa tanto em termos percentuais da quantidade de agrupamentos humanos quanto em termos espaciais e geográficos (Figura 1), o que garantiu o gradiente de isolamento requerido. Tal método amostral objetivou evitar o chamado efeito de 
pseudorepetição ${ }^{1}$ e autocorrelação espacial ${ }^{2}$. Dentre as comunidades Kalunga consideradas acessíveis, foram selecionadas para o presente estudo: Bom Jardim, Riachão, Diadema, Limoeiro, Ema e comunidade do Engenho. Já para as de difícil acesso, foram: Volta do Canto, Curral de Taboca, Maiadinha, Lagoa e Contenda.

\section{Análise dos Dados}

A análise dos resultados foi conduzida com o objetivo de caracterizar as comunidades quanto às condições socioeconômicas de vida, quanto aos hábitos alimentares locais, produção de autoconsumo e uso dos recursos naturais de subsistência. Esta parte do trabalho foi realizada por meio de entrevistas semiestruturadas e observações participantes.

As entrevistas semiestruturadas foram realizadas por meio de uma adaptação do método "Recordatório alimentar de 24 horas", conhecido como "O que você comeu ontem?", no qual foi aplicado um questionário com o intuito de levantar os itens alimentares do ponto de vista de hábito alimentar, o qual engloba mais a dimensão cultural e não nutricional. $\mathrm{O}$ método "Recordatório alimentar de 24 horas" é bastante difundido em pesquisas sobre consumo alimentar e ecologia de populações humanas [5,9]. Adicionalmente, a partir de uma lista com os principais itens alimentares normalmente consumidos no Brasil, foi registrada também a frequência de consumo local.

Embora se reconheça a limitação da adaptação do método "Recordatório alimentar 24 horas", devido à única aplicação com um membro das UDs, não inferindo, portanto, a variedade e sazonalidade da alimentação das comunidades, a sua importância para a obtenção de pistas e elementos sobre os hábitos alimentares locais é inegável, mesmo não havendo pretensão de investigação epidemiológica ou nutricional [25] 3. Portanto, a adaptação do "recordatório alimentar 24 horas" objetivou fornecer indicativos qualitativos para a caracterização dos diversos itens alimentares constituintes do hábito agroalimentar local.

As entrevistas foram realizadas com um adulto de cada unidade doméstica (UD) das comunidades, em Cavalcante foram 6 UDs no agrupamento de Volta do

${ }^{1}$ Pseudorepetições são observações dependentes que não fornecem informações novas e estatisticamente válidas.

2 De acordo com este princípio, quanto mais próximos os locais de coleta de dados, um em relação ao outro, maior é a probabilidade de haver valores redundantes e enviesados na amostragem.
Canto, 8 em Maiadinha e Engenho e 3 em Lagoa; nas comunidades de Teresina de Goiás foram $13 \mathrm{em}$ Limoeiro, 17 em Diadema e 9 em Ema. Nos agrupamentos de Monte Alegre foram $4 \mathrm{em}$ Contenda, 5 em Bom Jardim, 6 em Curral de Taboca e 6 UDs em Riachão. Nestas localidades investigou-se o tipo e origem do alimento consumido, frequência de consumo, dentre outras. Os entrevistados foram inquiridos também quanto às formas de uso dos recursos naturais de subsistência e produção de autoconsumo, quais os tipos de roça, se há caça e coleta e quais espécies são extraídas, dentre outras. Além disso, foram feitas perguntas quanto ao nível de renda, benefícios sociais recebidos, condições de moradia e saneamento, dentre outras, com o objetivo de traçar o perfil socioeconômico local. Uma vez que o objetivo do presente estudo é ecológico, relacionado ao modo de uso dos recursos de subsistência, principalmente, e não nutricional, destacase que a presente metodologia se fundamenta principalmente em Nardoto et al. [9] e Grangnani et al. [26].

Por meio dos dados levantados foram realizadas análises gráficas e tabulares para avaliação do padrão e frequência de consumo de determinados itens alimentares por comunidade. Além disso, foi possível realizar avaliações gráficas sobre os itens consumidos e produzidos localmente de acordo com as categorias de acesso ao meio urbano, ou seja, comunidades acessíveis e remotas do Sítio Histórico e Patrimônio Cultural Kalunga. De tal forma, os dados das questões semiestruturadas foram categorizados de forma binária para a presença (1) ou ausência (0) de um determinado item alimentar, tipo de produção de autoconsumo e ou fator socioeconômico (presença de energia elétrica, casa de alvenaria, esgoto, etc.), o que possibilitou por meio de gráficos uma melhor visualização dos resultados encontrados em campo. As análises gráficas foram realizadas de acordo com as categorias de acesso às comunidades, com intuito de salientar a possível influência do meio urbano nos costumes e práticas alimentares locais.

Em detalhes, a análise dos resultados foi realizada por meio da frequência relativa (\%) de entrevistados por comunidade que relataram o consumo ou produção de um determinado item alimentar. Quanto aos gráficos de frequência de consumo, foram estabelecidos pesos de acordo com a frequência de

\footnotetext{
3 Vale destacar que o presente método de entrevistas semiestruturadas com adaptação do "Recordatório alimentar 24 horas" foi adotado em publicações de Nardotto et al., 2011 e
} Grangnani et al., 2013. 
consumo semanal dos itens listados no questionário; valor 0 para itens nunca consumidos, 1 para itens raramente consumidos, 2 para aqueles com ao menos um consumo semanal e 3 para aqueles frequentemente consumidos [?. Este método é empregado para captar possíveis desvios nas respostas e a importância relativa dos itens alimentares regionais e da cidade na dieta local, de acordo com a frequência de consumo [25].

\section{RESULTADOS}

\section{Condições Sociais}

Considerável parcela das comunidades Kalunga próximas aos três centros urbanos (Monte Alegre, Teresina e Cavalcante) contam com moradias de alvenaria, exceção apenas àquelas notoriamente distantes e de difícil acesso (Tabela 1). Das comunidades amostradas apenas em três observou-se residências construídas com recursos alternativos locais, como adobe (tijolos de barro), barro jogado, madeira e palhoça, agrupamentos estes que além de distantes dos municípios limítrofes - Cavalcante, Monte Alegre e Teresina de Goiás - o acesso é extremamente difícil, realizado mais frequentemente por meio de tração animal.

Tabela 1. Condições socioeconômicas de moradia e auxílios governamentais por comunidades de difícil e fácil acesso, respectivamente.

\begin{tabular}{lccc}
\hline \multicolumn{1}{c}{$\begin{array}{c}\text { Benefícios sociais } \\
(\%)\end{array}$} & Difícil acesso & Comunidades & \\
\cline { 3 - 4 } & & 66,67 & Fácil acesso \\
\hline Bolsa Família & 37,04 & 70,37 \\
Aposentadoria & 3,70 & 37,04 \\
Pensão & & 22,22 & 14,81 \\
Outros & & Difícil acesso & 48,15 \\
\hline & Moradia & & Fácil acesso \\
\hline Madeira & $\mathbf{( \% )}$ & 29,70 & 0,00 \\
Alvenaria & & 62,96 & 75,93 \\
Adobe & & 7,41 & 18,52 \\
Palha & & & 5,56 \\
\hline
\end{tabular}


Figura 1. Comunidades Kalunga dos Municípios de Cavalcante, Monte Alegre e Teresina de Goiás. Setas pretas representam comunidades de difícil acesso e setas brancas comunidades mais acessíveis em relação às cidades.

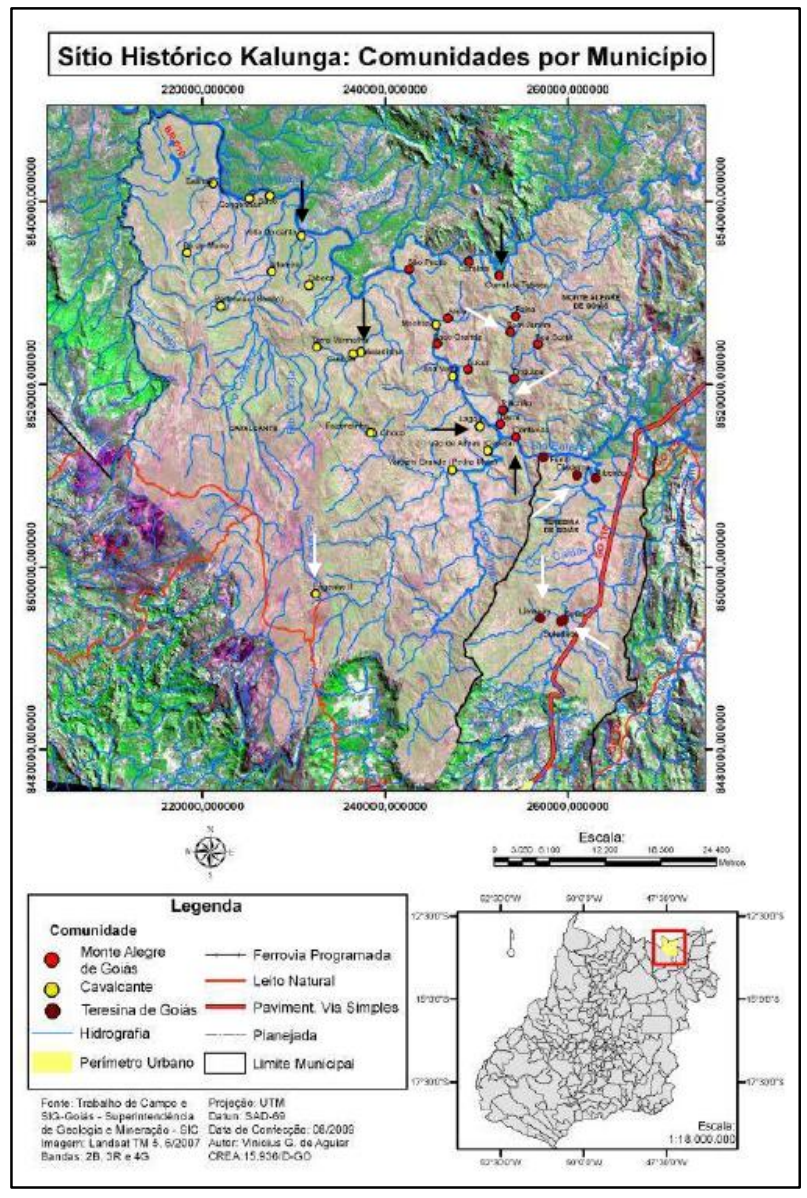

Fonte: Baiocchi et al., 2009.

Nas comunidades de fácil acesso (Figura 1), a presença de casas de alvenaria foi consideravelmente maior do que naquelas de difícil acesso (Tabela 1). Somado a isso, o número de casas de adobe, palha e madeira foi marcadamente superior na categoria de comunidades de difícil acesso, não sendo verificada nenhuma residência de madeira nos agrupamentos Kalunga de acesso mais facilitado (Tabela 1). Ainda em termos de habitação vale destacar o caso da comunidade Engenho em Cavalcante, comunidade de fácil acesso que além de ser um dos principais polos turístico da região da Chapada dos Veadeiros é o agrupamento mais atendido por programas assistenciais, com maior renda e com percentual mais alto de casas de alvenarias.

Nas comunidades Kalunga do município de Cavalcante, a maior parte das residências é tradicional, com paredes de adobe, "telhado" de palha e sem banheiro. Portanto, apesar da nítida diferença em termos de qualidade das construções, em várias comunidades observou-se a presença de ambos os tipos, alvenaria e adobe, onde uma se destina à permanência diurna e a outra ao repouso noturno e recepção de visitantes esporádicos. $\mathrm{Na}$ comunidade Maiadinha, munícipio de Cavalcante, um dos seus moradores ao ser interrogado sobre o motivo de tal comportamento, respondeu:

"Ah meu fio, esta casa nova é mais bonita, mas a gente tá costumado mais com a antiga, pra passar o dia é melhor (...)"

Nas comunidades acessíveis e com certa influência política regional predominaram residências de melhor qualidade, sendo o caso do Engenho que 
além de ser um dos principais polos turístico da região da Chapada dos Veadeiros, é o agrupamento mais atendido por programas assistenciais, com percentual mais alto de casas de alvenarias e piso de concreto. Outra exclusividade desta comunidade é a distribuição espacial totalmente distinta das casas em relação às demais comunidades do Sitio Histórico. Segundo palavras de um dos seus moradores mais influentes, presidente da Associação Kalunga:

“(...) quando comescamo a reunir o povo aqui no início da década de 90, momento em que acabamo de montar a associação, logo vimo que o kalunga tinha que se unir (...) então eu mesmo falei para construir as casas perto uma da outra (...) kalunga no mato não aparece pras autoridade!"

Em relação às políticas de assistência ou benefício social, além do Bolsa Família os Kalunga são assistidos em menor escala com aposentadoria, pensão (por invalidez, morte do cônjuge, etc.) e outras modalidades de benefício, como o auxílio maternidade (Tabela 1). Em Volta do Canto, uma das comunidades de mais difícil acesso no Sítio Histórico, a aposentadoria foi a maior fonte de benefício recebido, chegando a aproximadamente $65 \%$ dos moradores locais, haja vista a maior parte de moradores se concentrar na faixa etária acima dos 60 anos de idade. Relacionado ao gradiente de isolamento geográfico, a dinâmica demográfica nas comunidades mais distantes das cidades se caracteriza por uma pirâmide invertida, com maior número de moradores adultos e idosos do que jovens e crianças. Padrão distinto foi encontrado nas comunidades de Teresina, Engenho e Bom Jardim - agrupamentos acessíveis - onde a pirâmide se caracteriza por uma base mais larga, com maior percentual de jovens residentes.
Contrariamente às outras variáveis, há certa equivalência entre as comunidades quanto ao percentual de famílias beneficiadas pelos programas de assistência social, sendo que para o Bolsa Família o agrupamento Lagoa foi aquele que apresentou o maior índice de recebimento, com a totalidade de famílias sendo beneficiadas. Contudo, de forma geral as comunidades de fácil acesso ainda assim apresentam maior percentual de atendimento por políticas de assistência social (Tabela 1), principalmente em relação às outras modalidades de benefício. Estes benefícios somados às outras alternativas de geração de renda nas comunidades variam de $R \$ 100,00$ a $R \$ 400,00 \mathrm{em}$ média por família, reforçando principalmente a dependência do salário dos aposentados em detrimento a outras fontes, como a venda de farinha, principalmente, a partir da produção de mandioca.

\section{Uso dos Recursos Naturais e Hábitos Alimentares}

O milho é o terceiro item mais produzido nas roças Kalunga, menos que a mandioca e a abóbora, sendo que em algumas comunidades fica atrás somente da mandioca (Figuras 2, 3 e 4). Cabe à farinha ou droga ${ }^{1}$, como é chamado no Sítio Histórico, o papel principal na roça e economia Kalunga, evidenciado tanto a partir dos dados de produção (Figuras 2, 3 e 4) quanto dos de consumo, obtidos via adaptação do "recordatório alimentar 24 horas" (Tabela 2).

${ }^{1}$ Conforme destacado por Baiocchi (2006). 
Tabela 2. Análise alimentar com base na adaptação do "Recordatório Alimentar 24 horas", com percentual de itens alimentares consumidos nas comunidades de fácil de acesso nos remanescentes de quilombo Kalunga.

\begin{tabular}{|c|c|c|c|c|c|c|c|}
\hline \multirow[b]{2}{*}{ Alimentos } & \multicolumn{7}{|c|}{ Fácil acesso } \\
\hline & $\begin{array}{c}\text { Bom } \\
\text { Jardim }\end{array}$ & Riachão & Diadema & Ema & Limoeiro & Engenho & $\begin{array}{c}\text { Total } \\
(\%)\end{array}$ \\
\hline Arroz & 80,00 & 100,00 & 82,35 & 100,00 & 100,00 & 100,00 & 93,94 \\
\hline Feijão & 100,00 & 100,00 & 82,35 & 100,00 & 92,31 & 87,50 & 90,91 \\
\hline Carne Bovina & 40,00 & 40,00 & 33,33 & 41,18 & 44,44 & 23,08 & 62,50 \\
\hline Farinha & 40,00 & 33,33 & 41,18 & 55,56 & 53,85 & 25,00 & 40,91 \\
\hline Frango & 0,00 & 0,00 & 17,65 & 11,11 & 23,08 & 12,50 & 13,64 \\
\hline Refrigerante & 0,00 & 0,00 & 0,00 & 11,76 & 11,11 & 0,00 & 12,50 \\
\hline Abóbora & 20,00 & 33,33 & 17,65 & 22,22 & 15,38 & 37,50 & 24,24 \\
\hline Mandioca & 0,00 & 16,67 & 0,00 & 0,00 & 0,00 & 12,50 & 4,55 \\
\hline Batata & 0,00 & 0,00 & 0,00 & 0,00 & 0,00 & 12,50 & 3,03 \\
\hline Beterraba & 0,00 & 0,00 & 0,00 & 0,00 & 0,00 & 25,00 & 6,06 \\
\hline Cenoura & 0,00 & 0,00 & 0,00 & 0,00 & 0,00 & 12,50 & 3,03 \\
\hline Linguiça & 0,00 & 0,00 & 0,00 & 0,00 & 0,00 & 12,50 & 3,03 \\
\hline Soja & 0,00 & 0,00 & 0,00 & 0,00 & 0,00 & 12,50 & 3,03 \\
\hline Carne Suína & 0,00 & 0,00 & 0,00 & 0,00 & 0,00 & 0,00 & 12,50 \\
\hline Tomate & 0,00 & 0,00 & 0,00 & 0,00 & 0,00 & 12,50 & 3,03 \\
\hline Laranja & 20,00 & 0,00 & 0,00 & 0,00 & 0,00 & 0,00 & 1,52 \\
\hline Peixe & 40,00 & 33,33 & 11,76 & 11,11 & 15,38 & 0,00 & 13,64 \\
\hline Banana & 20,00 & 0,00 & 5,88 & 0,00 & 0,00 & 0,00 & 3,03 \\
\hline Jiló & 0,00 & 16,67 & 0,00 & 0,00 & 0,00 & 0,00 & 1,52 \\
\hline Macarrão & 0,00 & 16,67 & 0,00 & 0,00 & 7,69 & 0,00 & 3,03 \\
\hline Suco Natural & 0,00 & 0,00 & 16,67 & 5,88 & 0,00 & 7,69 & 0,00 \\
\hline Quiabo & 0,00 & 0,00 & 5,88 & 11,11 & 7,69 & 0,00 & 4,55 \\
\hline Suco Artificial & 0,00 & 0,00 & 0,00 & 5,88 & 0,00 & 0,00 & 0,00 \\
\hline Galinha Caipira & 0,00 & 0,00 & 0,00 & 0,00 & 11,11 & 7,69 & 0,00 \\
\hline Ovo & 0,00 & 0,00 & 0,00 & 0,00 & 7,69 & 0,00 & 1,52 \\
\hline Maxixe & 0,00 & 0,00 & 0,00 & 0,00 & 7,69 & 0,00 & 1,52 \\
\hline Hortaliças & 0,00 & 0,00 & 0,00 & 0,00 & 7,69 & 0,00 & 1,52 \\
\hline
\end{tabular}


Tabela 3. Análise alimentar com base na adaptação do "Recordatório Alimentar 24 horas", com percentual de itens alimentares consumidos nas comunidades de difícil de acesso nos remanescentes de quilombo Kalunga.

\begin{tabular}{lrrrrrr}
\hline \multirow{2}{*}{ Alimentos } & \multicolumn{7}{c}{ Difícil Acesso } & & Colta do \\
\cline { 2 - 7 } & Contenda & $\begin{array}{c}\text { Curral } \\
\text { Taboca }\end{array}$ & Lagoa & Maiadinha & $\begin{array}{c}\text { Total } \\
\text { Canto }\end{array}$ \\
\hline Feijão & 75,00 & 100,00 & 100,00 & 100,00 & 100,00 & 96,30 \\
Arroz & 75,00 & 100,00 & 100,00 & 87,50 & 100,00 & 92,59 \\
Farinha & 25,00 & 16,67 & 33,33 & 62,50 & 100,00 & 51,85 \\
Carne Bovina & 0,00 & 16,67 & 33,33 & 37,50 & 50,00 & 29,63 \\
Abóbora & 0,00 & 33,33 & 33,33 & 87,50 & 33,33 & 33,33 \\
Banana & 0,00 & 0,00 & 0,00 & 12,50 & 16,67 & 7,41 \\
Peixe & 75,00 & 33,33 & 33,33 & 0,00 & 16,67 & 25,93 \\
Cenoura & 0,00 & 0,00 & 0,00 & 0,00 & 16,67 & 3,70 \\
Suco Natural & 0,00 & 0,00 & 0,00 & 0,00 & 16,67 & 3,70 \\
Ovo & 0,00 & 0,00 & 0,00 & 0,00 & 16,67 & 3,70 \\
Laranja & 0,00 & 0,00 & 0,00 & 12,50 & 16,67 & 7,00 \\
Macarrão & 0,00 & 16,67 & 0,00 & 25,00 & 0,00 & 11,11 \\
Jiló & 0,00 & 0,00 & 33,33 & 12,50 & 0,00 & 7,41 \\
Tomate & 0,00 & 0,00 & 0,00 & 12,50 & 0,00 & 3,70 \\
Quiabo & 0,00 & 0,00 & 0,00 & 12,50 & 0,00 & 3,70 \\
Galinha Caipira & 0,00 & 0,00 & 0,00 & 12,50 & 0,00 & 3,70 \\
Carne Suína & 0,00 & 0,00 & 0,00 & 12,50 & 0,00 & 3,70 \\
Refrigerante & 0,00 & 0,00 & 0,00 & 12,50 & 0,00 & 7,41 \\
Suco artificial & 0,00 & 0,00 & 33,33 & 12,50 & 0,00 & 7,41 \\
\hline
\end{tabular}

Figura 2. Tipos de roça presentes nas comunidades Kalunga do município de Cavalcante - GO.

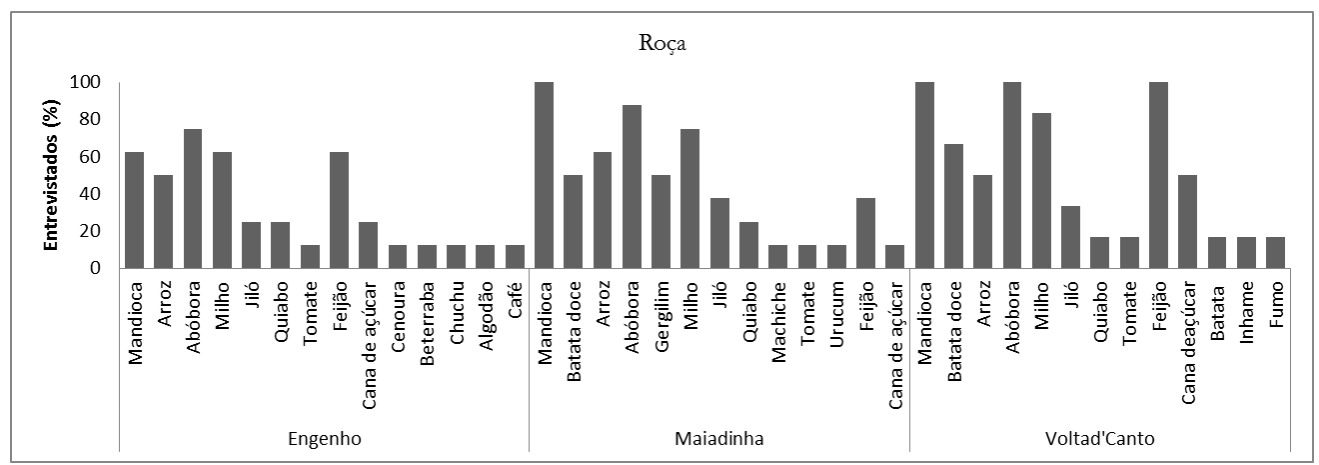


Figura 3. Tipos de roça presentes nas comunidades Kalunga do município de Monte Alegre - GO.

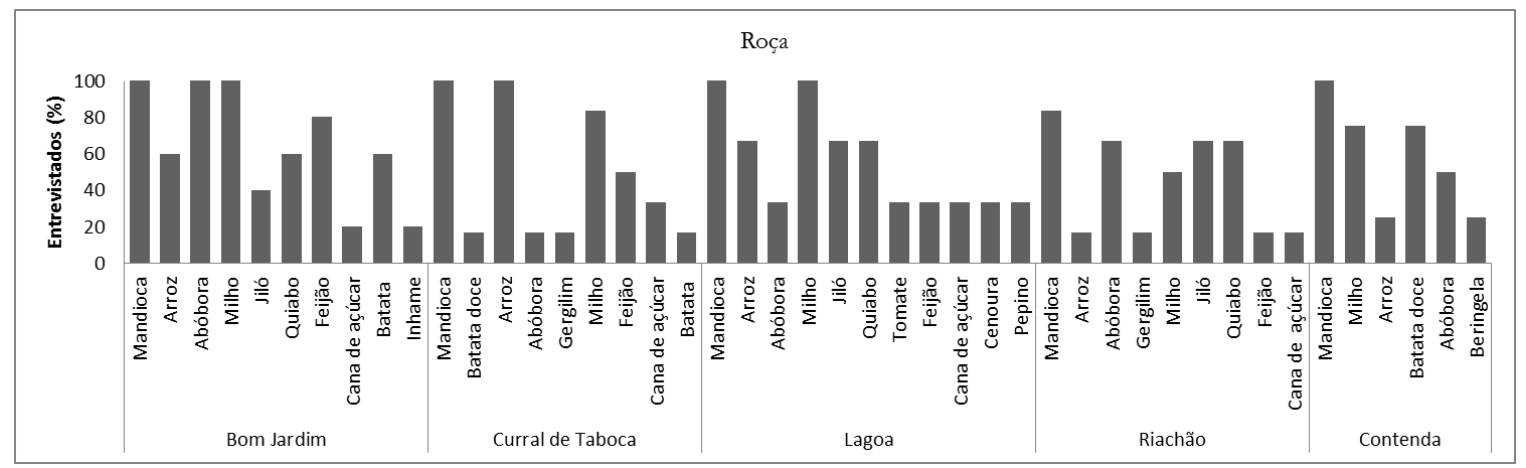

Figura 4. Tipos de roça presentes nas comunidades Kalunga do município Teresina - GO.

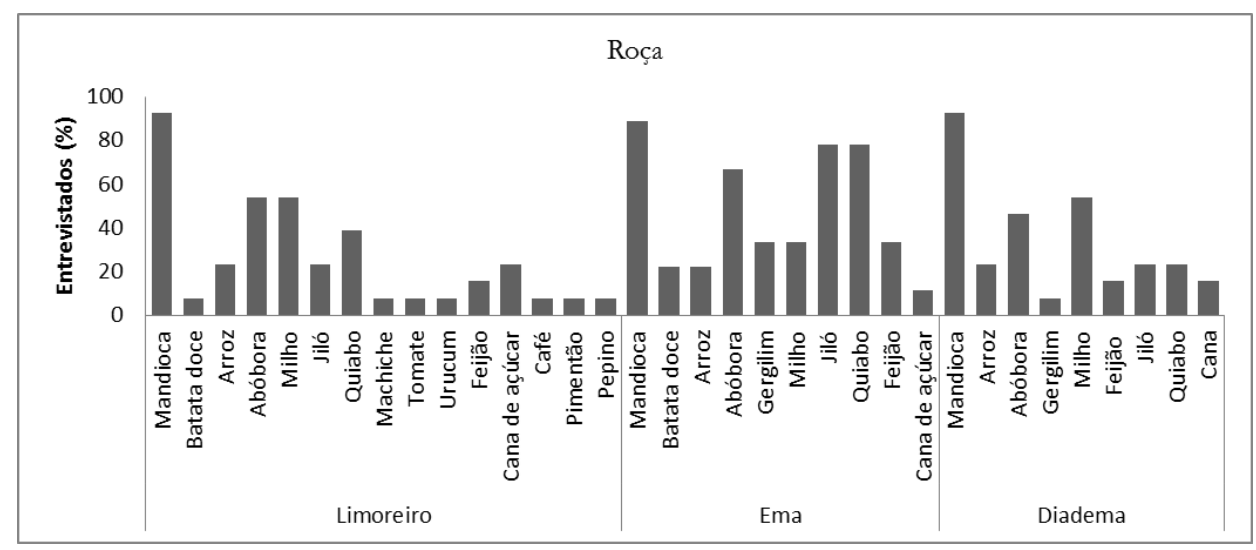

Se em termos de variedade de itens na roça não é possível estabelecer um padrão relativo ao grau de isolamento geográfico, quanto aos itens da cultura tradicional identifica-se que permanecem presentes nas comunidades de difícil acesso. Planta-se de tudo nos Kalunga, "onde há coragem para tornar a roça rica e farta", no dizer local, sendo que roças ricas e biodiversas, com plantações exuberantes, repletas de itens como arroz, mandioca, legumes, folhas, frutíferas, dentre outros, só foram vistas em comunidades remotas, de difícil acesso, como Lagoa, Volta do Canto e Maiadinha.
Em Maiadinha e Volta do Canto, por exemplo, observa-se a presença de gergelim, feijão de corda, batata doce, em percentual consideravelmente maior do que nas mais acessíveis (Figuras 2, 3 e 4). Além da mandioca, itens como jiló e quiabo também estão presentes em maior percentual nas roças das comunidades de difícil acesso (Figuras 2, 3 e 4).

Em Maiadinha, uma das comunidades geograficamente mais distantes do rio (Figura 1), dona Rosa, mãe de cinco filhos, cuja habitação é uma das poucas de adobe e piso de terra batida, forneceu o seguinte depoimento a respeito da produção: 
“(..) Kalunga que falar que passa fome por que não tem o que comer (...) que passa necessidade por que não tem terra boa pra plantar, que a plantação carece de água porque o rio é longe, é porque é preguiçoso, não tem braço pro trabaio (...) Meus fios tem tudo aqui, vou comprar pra que? O que precisam arrumo pra eles, planto tudo! O rio tá mais longe aqui, mas dô o meu jeito, como pode ver. Kalunga que passa fome épor que quer (...) dizem que a plantação não dá por que as formiga não deixa, mas por que aqui elas deixa?!"

Inúmeros foram os relatos femininos de descontentamento com a inatividade dos maridos, uma delas foi mais veemente: "O marido não pega nada, se não for a gente, as mulher, não tem nem peixe". Em Maiadinha, seu Juarez além de destacar alguns usos do milho, ressalta: "O povo hoje tá tudo modificado, não quer mais trabalho (...) antigamente se fazia o fubá e o angu de milho, o óleo de coco (Butiacapitata), hoje nada". Ainda em termos do papel do gênero quanto à atividade na roça, entre um dos moradores de Diadema foi colhido o seguinte depoimento:

"Quem não tem o comer épor que não quer, aqui não falta nada (...) a pobreza é da natureza do homem, pra quem tem corage não falta nada!"

Coincidência ou não este relato foi colhido na comunidade Diadema em Teresina - GO, um dos agrupamentos com maior percentual de auxílio Bolsa Família e menor variedade na roça dentre todas as comunidades de Teresina - GO (Figura 4). Já na comunidade de Limoeiro onde há maior estímulo à produção de farinha - devido ao incentivo do Programa Nacional de Fortalecimento da Agricultura Familiar PRONAF, observou-se maior variedade de itens na roça do que em Diadema (Figura 4).

De forma geral, os itens mais tradicionais da cultura Kalunga, o milho, a mandioca e abóbora, foram observados mais nas comunidades de difícil acesso do que naquelas de influência direta dos municípios limítrofes. Já quanto à criação de animais nos Kalunga, esta se resume ao curral de gado, chiqueiro de porco e poleiro de galinhas, sendo que a criação de animais para o consumo entre os Kalunga foi perceptivelmente menor nas comunidades de Teresina de Goiás (Limoeiro, Emas e Diadema). No Engenho, apesar do percentual apreciável de criação de animais, galinhas principalmente, boa parcela se destina à troca por itens alimentares de supermercado com os vizinhos ou turistas. Uma das moradoras da comunidade relatou que: "Crio galinha caipira pra trocar pelo frango da cidade (...) a carne do caipira é muito dura, não gosto."
Já quanto aos quintais de cultivo, embora a variedade da produção seja maior nas comunidades mais próximas - Ema, Limoeiro, Diadema, dentre outras - o percentual de consumo foi consideravelmente baixo em relação aos quintais dos agrupamentos de difícil acesso, como Maiadinha, Volta do Canto, Contenda, dentre outras (Tabelas 2 e 3). Itens como mexerica, manga, abacaxi, limão, acerola, mamão, dentre outros, estiveram bem presentes em boa parte das comunidades, com destaque para banana e laranja, que por serem as frutas mais apreciadas foram as mais produzidas, sendo consumidas entre $3 \%$ e $1,5 \%$ nas comunidades de fácil acesso e entre 7,41\% e 7\% nas de difícil acesso, respectivamente (Tabelas 2 e 3 ).

Em relação ao consumo alimentar, devido à simplicidade do café da manhã, composto basicamente por café extremamente adocicado e bolachas de água e sal com margarina, será dado maior enfoque às outras refeições, principalmente almoço, haja vista que o jantar normalmente é uma repetição do almoço nas comunidades.

De tal forma, a alimentação nas comunidades Kalunga se mantém estruturada nos alimentos tradicionais da cultura local, arroz e feijão, prioritariamente, seguidos pela farinha (Tabelas 2 e 3 ). Segundo relato da maioria dos entrevistados, estes itens são indispensáveis para a alimentação diária, sendo o tripé da dieta local que quando ausente causa a sensação de não saciedade.

Os resultados do "recordatório alimentar" salientam para todas as comunidades um alto consumo de arroz e feijão no almoço (Tabelas 2 e 3). No entanto, este alto consumo não é acompanhado na mesma proporção pela produção de tais itens na roça (Figuras 2 a 4). Outro dado importante refere-se ao padrão de produção e consumo de farinha, oposto ao verificado para o arroz e o feijão. Enquanto que o consumo da farinha de mandioca já não tem mais a mesma importância na alimentação local, a produção de mandioca foi expressivamente maior dentre todas as outras (ver Figuras 2 a 4 e Tabelas 2 e 3).

Mesmo não sendo um percentual expressivo, as comunidades de Engenho e as três de Teresina de Goiás (Diadema, Limoeiro e Ema) foram as únicas do Sítio Histórico onde se registrou relatos de consumo de frango de granja (Tabela 2). $\mathrm{Na}$ comunidade do Engenho, uma moradora chegou a frisar que: 
"não gosto da carne da galinha caipira, ela é muito dura e depois de tanto tempo comendo acho que enjoei do gosto. Quando aparece alguém querendo eu troco o caipirão pelo frango mesmo!"

Nesta linha, os resultados de frequência de consumo alimentar evidenciam um consumo consideravelmente menor de frango de granja nas comunidades de difícil acesso (Figura 5). Dentre os agrupamentos acessíveis, os de Teresina de Goiás foram aqueles onde o consumo do frango de granja foi o mais acentuado, em média realizado quase duas vezes por semana (Figura 6). Além do frango, o consumo de carne bovina também foi maior nas comunidades mais acessíveis (Figura 5). Já o consumo de frutas foi maior que nas de difícil acesso (Figura 5). Somado a isso, naqueles agrupamentos mais próximos às cidades $\mathrm{O}$ consumo de alimentos industrializados como doces, embutidos, refrigerantes, dentre outros, também foi maior (Tabelas 1 e 2 e Figura 5).

Figura 5. Frequência de consumo semanal nas comunidades Kalunga de fácil e difícil acesso, respectivamente.

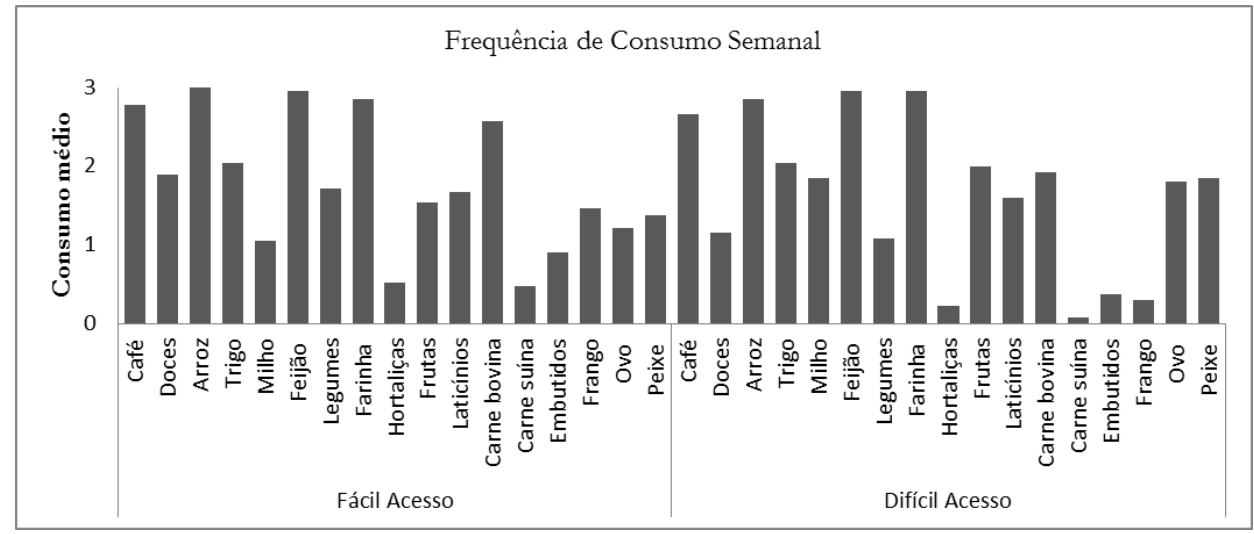

Figura 6. Frequência de consumo semanal nas comunidades Kalunga dos Municípios de Cavalcante Teresina e Monte Alegre, respectivamente.

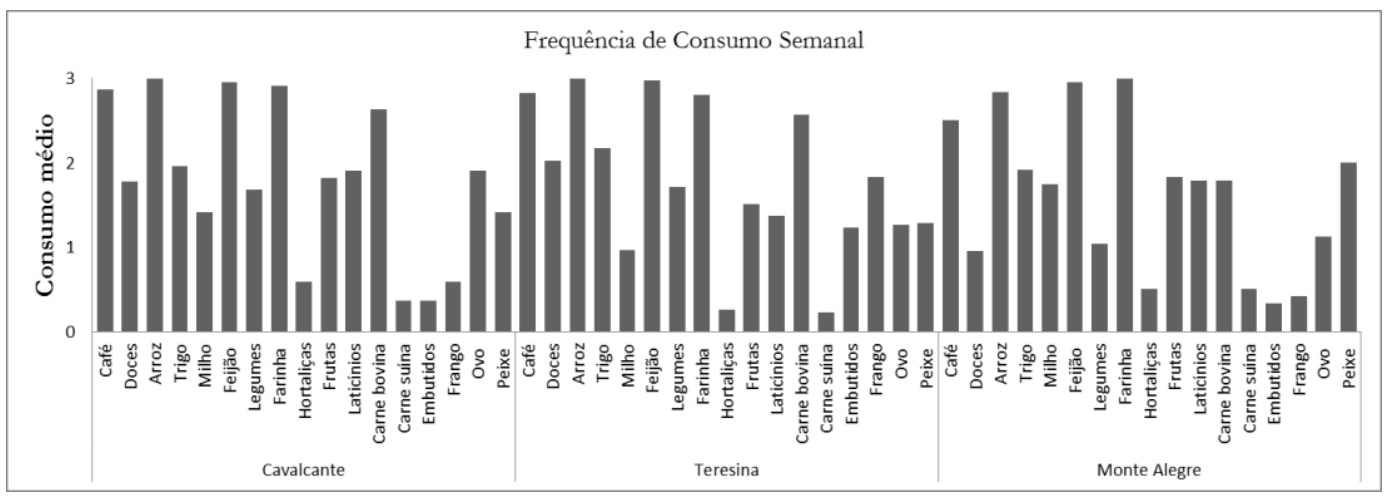

Outro padrão alimentar de distinção entre as comunidades de difícil e fácil acesso foi encontrado para o consumo de peixe. O consumo de peixe se mostrou pouco expressivo em termos percentuais gerais, embora recorrente em quase todas as comunidades entrevistadas (Figuras 5 e 6 ). A única 
exceção é a comunidade Contenda, localizada às margens do Paranã, onde o tripé da alimentação é composto por arroz, feijão e peixe (Tabela 3). A farinha está presente, mas não na mesma proporção que os itens citados (Tabela 3).

\section{DISCUSSÃO}

\section{Condições Socioeconômicas}

Em se tratando de uma comunidade de remanescentes de quilombo, com território bem delimitado, cultura e etnia que remetem à afrodescendência histórica, a condição de vida nos Kalunga não é homogênea, o que tem a ver tanto com fatores espaciais, que aproximam determinados agrupamentos do modo de vida urbano, quanto com fatores sociais e mesmo políticos.

Quanto ao material de revestimento das moradias, o gradiente de isolamento geográfico ou a proximidade com o meio urbano demostrou relação com a qualidade, o que também pode ser explicado pelo maior aporte de renda à medida que o acesso a cidade se torna mais fácil. Exemplo disso pode ser visto na comunidade Engenho, a qual possui residências de alvenaria e com distribuição espacial apreciavelmente diferente das demais comunidades, como destacado nos resultados.

Apesar da distinção, o padrão residencial encontrado no Engenho tem demonstrado o fortalecimento do grupo no que concerne aos benefícios sociais captados, o que remete à discussão de que o desenvolvimento local exige que haja um mínimo de organização social para que os diferentes atores possam ser os reais protagonistas da transformação em curso [27].

Um fator de grande importância para a caracterização das condições de vida é a renda advinda de programas de assistência social [23]. A renda média ${ }^{1}$ nos Kalunga é dependente do salário dos aposentados (Tabela 1). $\mathrm{O}$ acrescimento salarial advindo da aposentadoria reforça e legitima o papel de liderança dos idosos em relação aos demais membros da comunidade, observando-se ainda o hábito rotineiro de pedido de benção por parte dos mais jovens aos mais velhos. O rendimento do idoso além de abastecer a sua própria unidade doméstica, beneficia também os parentes de outras localidades, sendo responsável por grande parcela de manutenção das condições econômicas de vida nos Kalunga.

Não especificamente à aposentadoria, já que é um direito inquestionável, mas as políticas de transferência de renda podem ser consideradas um filtro que têm comprometido o alcance do desenvolvimento socioeconômico, justamente por não serem realizadas de acordo com as tradições e herança cultural local [28]. Ao desestimularem o esforço individual e o aumento da capacitação técnica no campo estas políticas podem causar impactos nas atividades cotidianas de produção agrícola e extrativista e, consequentemente, na alimentação. Veiga ${ }^{[29]}$ propõe que o auxílio às ações locais de desenvolvimento rural seja de natureza contratual, honrando-se determinados compromissos de forma que a participação do governo federal não se restrinja apenas ao repasse de verba.

Quanto à diferença em relação aos benefícios sociais e fontes de renda entre as comunidades acessíveis e de difícil acesso, de acordo com o observado em campo levantam-se duas questões: primeiro, que as famílias das comunidades mais isoladas, como Curral e Lagoa, reconhecidamente vivem em situação de maior vulnerabilidade e de menor acesso aos recursos econômicos, demandando maiores cuidados assistenciais. Segundo, além do escoamento facilitado da farinha, as comunidades mais próximas dispõem de mais alternativas de geração de renda, ecoturismo por exemplo.

Portanto, aumentar as fontes alternativas de geração de renda pode ser uma opção para que os programas de assistência social deixem de ser imprescindíveis aos olhos da população. Nesta linha de raciocínio, Baiocchi et al. [23] advertem que há ricas possibilidades de geração de renda no seio do próprio conhecimento tradicional Kalunga, contudo estas devem ser uma extensão de suas atividades cotidianas e não imposições de um sistema de produção próprio da sociedade urbana.

\section{Hábitos Alimentares e Uso dos Recursos Naturais}

A partir da caracterização socioeconômica acima e dos resultados alimentares encontrados, observa-se certa dependência da cidade em relação aos produtos de supermercado e uma redução no plantio

${ }^{1}$ Variável em torno de $\mathrm{R} \$ 100,00$ a R $\$ 400,00$. 
de autoconsumo nos Kalunga, principalmente nas comunidades próximas aos municípios limítrofes, Engenho, as de Teresina de Goiás, Riachão e Bom Jardim. Contudo, mesmo diante de tais mudanças a tríade tradicional - arroz, feijão e farinha - ainda se mantém bem presente no cotidiano das comunidades Kalunga.

Validando tais resultados, Baiocchi ${ }^{[24]}$ ressalta que os produtos típicos da agricultura de subsistência dos Kalunga são a mandioca, o arroz, o feijão, o milho e a cana, tendo a mandioca maior importância econômica pelo seu valor comercial e também alimentício, contudo, sobressaindo o arroz como item principal de consumo. Neste sentido, Baiocchi [24] destaca também algumas variedades conhecidas de arroz que são repassadas pelos Kalunga mais velhos aos descendentes, como: arroz mearim-branco e vermelho, garpa, pratão e novato.

Referente ao consumo e produção da farinha, a partir dos resultados evidencia-se uma mudança no papel da farinha de fonte energética para meio de renda. Este resultado poderia significar uma prova do processo de transição e interferência da modernidade nos hábitos alimentares tradicionais locais, já que a farinha historicamente faz parte do cardápio típico dos Kalunga, como salientado antes. Entretanto, nas comunidades de Teresina de Goiás, nos agrupamentos Diadema, Ema e Limoeiro o tripé alimentar (arroz, feijão e farinha) permanece reafirmado (Figura 4), o que pode ser explicado pela iniciativa de construção de casas de farinha nestas comunidades Kalunga de Teresina de Goiás pelo Programa Nacional de Fortalecimento da Agricultura Familiar (PRONAF), com o caráter de estímulo do ofício tradicional. Tal política de perfil não assistencialista, além de possibilitar a manutenção das tradições e reafirmação biocultural dos costumes agroalimentares promoveu a melhoria das condições de vida (Tabela 1).

Assim, apesar da constante mudança socioeconômica pela qual as comunidades rurais estão passando, o estímulo do ofício tradicional pode potencializar a capacidade de assimilação dos elementos culturais de fora e de reelaboração de novos de acordo com as peculiaridades locais, nos dizeres de Durham [21] e Cunha e Almeida [22]. Tal afirmação evidencia-se a partir do caso da farinha que, em termos laborais, é a maior fonte de renda dos Kalunga, se não a única, girando em torno de $\mathrm{R} \$ 300,00$ a $\mathrm{R} \$ 500,00$ por família em períodos de boa safra. Embora não seja um valor considerável para os padrões do meio urbano, no local é uma renda significativa.

O ofício da farinha inserido no espaço da oficina e direcionado à função do trabalho reproduz aspectos importantes da cultura material, como ferramentas de uso na lida familiar, tapiti, tear, pilão, peneiras, gamelas, enxadas, dentre outros [24]. A oficina, portanto, é o lugar de preparação da farinha de mandioca, desde o seu processamento até a embalagem em sacos de algodão que, após ser colhida, descascada e lavada, segue para uma gamela onde será ralada em um pau de angico [24].

Apesar da relativa manutenção do tripé alimentar nas refeições mais importantes do dia, almoço e jantar, sendo este na maioria absoluta das vezes uma simples repetição do cardápio do almoço, a dieta nas comunidades mais próximas às cidades apresenta mais alterações em relação ao hábito tradicional, mais doces, embutidos, refrigerantes e menos mandioca, peixes e outros itens tradicionais, como visto nos resultados (Tabelas 2 e 3). A principal alteração refere-se à presença do frango de granja em lugar do caipira, o que corresponde com os resultados de criação de animais anteriormente abordados. De acordo com tal resultado, Nardotto et al. ${ }^{[9]}$ argumentam que a presença de frango congelado proveniente de regiões urbanas, especificamente em comunidades da Amazônia, tem dois agravantes. Primeiro que não agrega valor local ao priorizar o consumo de itens alimentares de fora e, segundo, que o transporte em barco fluvial sob condições de armazenamento questionáveis faz com que os produtos já cheguem descongelados ao consumidor final, aumentando assim o risco de doenças e intoxicação alimentar.

O consumo de itens não habituais provavelmente tem a ver com o interesse pelo diferente e com o aspecto cultural de escolha de alimentos que aparentemente conferem prestígio social [9]. O consumo de carne vermelha, por exemplo, é considerado um sinal de progresso em comunidades rurais isoladas, haja vista ser realizado apenas esporadicamente em eventos festivos [30]. Quanto a isto, na comunidade Limoeiro Sr. Simplício relatou que o desenvolvimento e a melhoria das condições de vida nos Kalunga permitiram à sua família o maior consumo de carne, tanto de gado quanto de frango. 
Em relação ao peixe, alguns fatores podem explicar a sua relativa ausência na alimentação Kalunga, como a falta de costume histórico do povo. No entanto, o mais provável é que este padrão resulte mais do processo de transição agroalimentar, haja vista que nas comunidades de difícil acesso a frequência de consumo de pescado é apreciavelmente maior (Figura 5). Este processo que gradativamente desloca a comunidade de sua dinâmica biocultural tradicional pode explicar também o maior consumo de embutidos, doces, laticínios e frango nas comunidades acessíveis, principalmente em Teresina de Goiás (Figuras 5 e 6 ).

Quanto ao consumo de peixes na comunidade Contenda, as causas prováveis da manutenção se devem ao seu isolamento, proximidade com o rio e o desmantelamento da estrutura social. Encravada em meio a uma cadeia de montanhas onde o tempo parece ter parado, a sensação que ali se tem é de retorno aos séculos passados. Às beiras do rio Paranã (Figura 1), lugar de água cristalina e de beleza sem igual, há carência de toda e qualquer ordem de serviços públicos disponíveis, mas há abundância de coragem e recursos naturais para a subsistência. Segundo Baiocchi [24], Contenda já foi composta por mais de meia centena de pessoas, estando hoje reduzida com a maioria de mulheres, em que os companheiros foram buscar trabalho na cidade, o que pode justificar a alimentação simplificada, uma vez que a parte mais exigente da roça - capina e roçagem - geralmente é responsabilidade dos homens.

Assim, considerando o cenário de relativo aumento de alimentos industrializados na dieta das comunidades Kalunga, notou-se que alguns fatores têm maior peso que outros no sistema agroalimentar deste povo, exercendo maior influência nas escolhas do cotidiano. A compra de alimentos em supermercados das cidades limítrofes parece ter sido uma prática adquirida recentemente, em consonância com o advento de auxílios governamentais, como a aposentadoria, pensão por invalidez, bolsa-família, auxílio maternidade, dentre outros. Vale destacar o maior percentual de famílias atendidas por estas modalidades de assistência do governo entre as comunidades de fácil acesso (Tabela 1), o que possivelmente é um fator de grande influência nas mudanças de hábitos alimentares e produção de autoconsumo.

Ao proporcionar um bom mapeamento dos itens alimentares presentes no cotidiano local, os dados do "recordatório" enriquecem a discussão sobre uma perspectiva em que o alimento atua como elo do homem com a natureza e com o universo biocultural socialmente reproduzido através da produção de subsistência. Entretanto, apesar da perpetuação da tríade - arroz, feijão e farinha - em comunidades acessíveis e isoladas (Figura 5), o que remete à capacidade de reorganização ou reelaboração e reafirmação dos hábitos tradicionais frente à influência externa, da cidade, os sinais de transição agroalimentar são vários e não podem ser descartados.

A substituição de itens tradicionais por industrializados também foi encontrado entre comunidades ribeirinhas da Amazônia por Nardoto et. al. [9], que verificaram o aumento gradual de itens alimentares como açúcar, carne vermelha e frango de granja substituindo alimentos tradicionais como peixe e mandioca à medida que aumenta o acesso aos centros urbanos e aos produtos de supermercado. Piperata et al. [10] encontraram resultados semelhantes em estudos com ribeirinhos da Amazônia.

Estes verificaram que as transformações econômicas advindas do maior acesso à aposentadoria, ao trabalho assalariado e ao recebimento de bolsa família tem intensificado a transição alimentar e diminuído a produção de subsistência. A renda extra de programas como o Bolsa Família tem alterado o estilo de vida das comunidades rurais na Amazônia e as suas estratégias de uso dos recursos de subsistência, ocasionando o abandono do cultivo tradicional de mandioca [11].

A despeito dos sinais de transição agroalimentar, não se pode inferir ainda que tal processo culminará em um desarranjo dos caracteres bioculturais que possibilitaram a sobrevivência dos povos tradicionais. No entanto, a transição agroalimentar já mostra alguns indícios, mas a capacidade de reorganização cultural e ajuste às novas demandas também é possível, fato observado naquelas localidades onde foram fornecidas condições de vida, de trabalho e automanutenção de acordo com os costumes e hábitos locais. No caso, as comunidades Limoeiro e Ema de Teresina - GO, beneficiadas pela criação de casas de farinha.

Finalmente, a partir dos resultados encontrados destaca-se que as comunidades tradicionais realmente podem estar passando por um processo de transição agroalimentar em direção à cidade. De acordo com o contexto algumas variáveis 
poderão influenciar mais ou menos no processo e nos ajustes às mudanças, haja vista que o consumo de alimentos além de não se reduzir somente às questões econômicas [31], em comunidades rurais tradicionais também é acompanhado por práticas agrícolas de autoconsumo e usos variados dos recursos naturais de subsistência. Portanto, considerando a complexidade do assunto, torna-se necessário avaliar a influência multifatorial da questão, o social, o econômico, da agricultura e uso dos recursos, na transição agroalimentar e na capacidade de reorganização e ajuste frente ao contato com a modernidade e às flutuações do mercado.

\section{CONSIDERAÇÕES FINAIS}

Numa dinâmica global de transição, o presente trabalho levanta questões referentes não apenas à problemática da alimentação moderna, mas também às consequências do modo de vida urbanizado em comunidades tradicionais rurais. Salientando as mudanças conferidas pelo maior acesso ao meio urbano e itens industrializados, reforça-se um ponto de vista de impactos conjuntos no sistema agroalimentar de povos tradicionais, na alimentação, produção agrícola de autoconsumo e nos usos dos recursos naturais de subsistência.

De tal forma, os indícios em favor da transição agroalimentar e da alteração dos usos dos recursos são evidentes, mas diante dos inúmeros fatores que exercem influência na alimentação, a complexidade do fenômeno de transição agroalimentar precisa ser investigada sob diferentes formas para uma melhor associação entre o desenvolvimento e as mudanças nos modos de vida destas comunidades tradicionais. Portanto, trabalhos futuros deverão concentrar esforços em quais fatores são preponderantes para uma tomada de decisão em relação ao processo de transformação no campo e, especificamente, em comunidades tradicionais rurais.

Enfim, a partir dos sinais de transição agroalimentar pondera-se que apesar de um possível desarranjo da alimentação tradicional, as comunidades tradicionais rurais possuem uma capacidade inata de reorganização de novos padrões frente à expansão da economia de mercado. Contudo, devido à amplitude das mudanças globais, os desafios de reprodução sociocultural em um contexto em transição demandarão ajustes que vão além de simples iniciativas de transferência de renda. Além de políticas públicas orientadas ao fortalecimento das condições socioeconômicas locais, este processo requer conscientização comunal dos problemas gerados pela transição agroalimentar e uma tomada de decisão proativa por parte dos atores locais.

\section{AGRADECIMENTOS}

À Fundação de Amparo à Pesquisa do Estado de São Paulo (FAPESP) que por meio do processo FAPESP 2011/08686-3 (bolsa de doutorado) possibilitou o desenvolvimento deste trabalho.

\section{REFERÊNCIAS}

[1] Tardido AP, Falcão MC. O impacto da modernização na transição nutricional e obesidade. Rev Bras Nutr Clin. 2006;21(2):117-124.

[2] Carneiro H. Comida e sociedade: uma história da alimentação. Rio de Janeiro: Campus; 2003.

[3] Moran E. A ecologia humana das populações da Amazônia. Petrópolis: Vozes; 1990.

[4] Sahlins M. A primeira sociedade da afluência. In: Carvalho, EA (organizador). Antropologia Econômica. São Paulo: Editora Ciência Humanas; 1978. p. 7-44.

[5] Murrieta RSS, Dufour DL, Siqueira AD. Food consumption and subsistence in three caboclo populations on Marajó Island, Amazonia, Brazil. Hum Ecol. 1999;27(3):455-75.

[6] Poulain JP. Sociologia da alimentação: os comedores e o espaço social alimentar. Florianópolis: UFSC; 2004.

[7] Piperata BA. Nutritional status of Ribeirinhos in Brazil and the nutrition transition. Am J Phys Anthropol. 2007;133(2):868-78.

[8] Pollan M. Em Defesa da Comida: um manifesto. Rio de Janeiro: Intrínseca; 2008.

[9] Nardoto GB, Murrieta RSS, Prates LEG, Adams C, Garavello MEPE, Schor T, et al. Frozen chicken for wild fish: Nutritional transition in the Brazilian Amazon region determined by carbon and nitrogen stable isotope ratios in fingernails. Am J Hum Biol. 2011;23(5):642-50.

[10] Piperata BA, Spence JE, Da-Gloria P, Hubbe M. The Nutrition Transition in Amazonia: Rapid Economic Change and its Impact on Growth and Development in Ribeirinhos. Am J Phys Anthropol. 2011;146:1-13. 
[11] Pfeiffer JM, Dun S, Mulawarman B, Rice KJ. Biocultural diversity in traditional rice-based agroecosystems: indigenous research and conservation of mavo (Oryza sativa L.) upland rice landraces of eastern Indonesia. Environ Dev Sustainability. 2006;8(4):609-625.

[12] Vandermeer JH. The ecology of agroecosystems. Massachusetts: Jones and Bartlett Publishers; 2011.

[13] Gliessman SR. Agroecologia: processos ecológicos em agricultura sustentável. Porto Alegre: UFRGS; 2009.

[14] Altieri M. Agroecologia: a dinâmica produtiva da agricultura sustentável. Porto Alegre: Editora da UFRGS; 2009.

[15] Guzmán ES. De la sociología rural a la agroecología. Perspectivas agroecológicas. São Paulo: Icaria Editorial; 2006.

[16] Silva AL, Begossi A. Biodiversity, food consumption and ecological niche dimension: a Study Case of the Riverine Populations from the Rio Negro, Amazonia, Brazil. Environ Dev Sustainability. 2007;11(3):1-24.

[17] Murrieta RSS, Dufour DL. Fish and farinha: protein and energy consumption in Amazonian Rural communities on Ituqui Island, Brazil. Ecol Food Nutr. 2004;43(3):231-255.

[18] Aguiar GFS. Nutrição e adaptação humana em áreas de pesca na Amazônia: sugestões para políticas em saúde. Boletim do Museu Paranaense Emílio Goeldi Ciências Humanas. 2006;1(2):129-138.

[19] Arruda R. Populações Tradicionais e a Proteção dos Recursos Naturais em Unidades de Conservação. Ambient Soc.1999;5:79-92.

[20] Diegues ACS. O mito moderno da natureza intocada. São Paulo: Editora Hucitec; 1998.

[21] Durham ER. Dinâmica da cultura: ensaios de antropologia. São Paulo: Cosac Naify; 2004.
[22] Cunha MC, Almeida MWB. Populações Tradicionais e Conservação Ambiental. In: Cunha MC. Cultura com aspas e outros ensaios. São Paulo: Cosacnaify; 2009. p. 237-268.

[23] Baiocchi MN, Carvalho AF, Baiocchi EG, Da Silva KL, Carvalho FGBV, Salomão MAS, et al. Secretaria do Estado de Políticas para Mulher e Promoção da Igualdade Racial (GO), Diagnóstico Situacional das Comunidades do Sítio Histórico e Patrimônio Cultural Kalunga. Goiânia; 2009.

[24] Baiocchi MN. Kalunga: Povo da Terra. Goiânia: Edufg/Cegraf; 2006.

[25] Fisberg RG, Marchioni DML. Manual de avaliação do consumo alimentar em estudos populacionais: a experiência do inquérito de saúde em São Paulo (ISA)/Universidade de São Paulo. Faculdade de Saúde Pública. Grupo de Pesquisa de Avaliação do Consumo Alimentar. São Paulo; 2012.

[26] Gragnani JG, Garavello MEPE, Silva RJ, Nardoto GB, Martinelli LA. Can stable isotope analysis reveal dietary differences among groups with distinct income levels in the city of Piracicaba (southeast region, Brazil)? J Hum Nutr Diet. 2013;10:1-7.

[27] Graziano da Silva J. Velhos e novos mitos do rural brasileiro. Estud Av. 2001;15(43):37-50.

[28] Sen AK. Desenvolvimento como Liberdade. São Paulo: Companhia das Letras; 2000.

[29] Veiga JE. O Brasil rural ainda não encontrou seu eixo de desenvolvimento. Estud Av 2001;15(43):101-119.

[30] Zaluar A. A Máquina e a Revolta: as organizações populares e o significado da pobreza. 2. ed. São Paulo: Brasiliense; 2000.

[31] Bleil SI. O Padrão Alimentar Ocidental: Considerações sobre a mudança de hábitos no Brasil. Cadernos de Debate. 1998;6:1-25. 